Neurology

\section{The term diplegia should be abandoned}

\section{A F Colver, T Sethumadhavan}

Use of the term has served to confuse classification and obscure interpretation of epidemiological and clinical studies

$\mathrm{F}$

rom the writings of Freud onwards there is broad agreement on the definition of cerebral palsy (CP) but attempts to classify it, based on brain pathology, timing of postulated insult, aetiology, or clinical syndrome, taking account of one or more of neurological findings, distribution, and associated impairments, have been less successful.

Any syndrome must be clearly defined, meaningful, reliable, and used consistently by different people. A few $\mathrm{CP}$ syndromes such as choreoathetosis with deafness caused by bilirubin encephalopathy and ataxia caused by hydrocephalus have stood the test of time and are reviewed by Ingram. ${ }^{1}$ However, we think that diplegia is not a description of a valid category or syndrome and use of the term has served to confuse classification and obscure interpretation of epidemiological and clinical studies. We draw on historical papers and our own new analyses of recent published epidemiological papers to argue that the term diplegia should be abandoned.

\section{HISTORICAL OVERVIEW OF USE OF TERM DIPLEGIA}

Table 1 summarises important classifications of the past 150 years which we shall discuss with respect to their use of the term diplegia.

William Little ${ }^{2}$ first described the syndrome complex of cerebral palsy in 1862. His paper proposed a link between abnormal parturition, difficult labour, premature birth, asphyxia neonatorum, and physical deformities, which he described lucidly. He did not use the term diplegia.

In 1890, Sachs and Peterson proposed a classification which linked clinical syndrome to timing of the insult, ${ }^{3}$ and introduced diplegia and paraplegia as separate categories.

In 1893, Freud considered cerebral palsy to be caused not just at parturition but also sooner in pregnancy because of "deeper effects that influenced the development of the foetus". ${ }^{4}$ Freud was the first to use the term "cerebral diplegia", which covered all bilateral cerebral palsies, including non-spastic types.

Further classifications appeared in the 1950s. ${ }^{56}$ As table 1 shows, Minear's ${ }^{6}$ was more a descriptive grid than a classification, and for him diplegia was "paralysis affecting like parts on either side of the body".

In Ingram's classification of $1955,{ }^{711}$ spastic diplegia was described "as a condition of more or less symmetrical paresis of cerebral origin more severe in the lower limbs than the upper and dating from birth or shortly thereafter". He qualified the disorder with an association with prematurity and lesser incidence of mental retardation, pseudobulbar palsy, and seizures compared to quadriplegics. He also described its clinical evolution through the stages of hypotonia, dystonia, and rigidity. ${ }^{12}$ Later in his 1966 review article "The neurology of cerebral palsy", he re-emphasised what he regarded as the unequivocal distinction between spastic diplegia and other bilateral cerebral palsies. ${ }^{13}$

In 1959 in England, ${ }^{8}$ The Little Club presented a definition and classification of cerebral palsy: "In diplegia there is affection of the muscles of all four limbs. The lower limbs are the more affected." The classification had an additional category "atonic diplegia", but the reasoning presented in the article for this category and other aspects of the classification are difficult to follow. By 1964 the problems were apparent, and an annotation $^{14}$ recommended that description should be based on clinical features and that attempts to define certain syndromes combining clinical aetiological and pathological features should be avoided. In particular the idea of a diplegic syndrome should be avoided.

In their first epidemiological report in 1975, the Hagbergs ${ }^{9}$ used a classification with a definition of diplegia similar to Ingram's. Hypertonic cases were diplegic where the lower limbs were more affected than the upper ones. Cases were regarded as diplegic even when they exhibited severe generalised damage and "might have been classified as tetraplegia by other investigators". Their classification had an additional category of "ataxic diplegia" where the children had diplegia with ataxic traits, especially dysynergia and intention tremor in the upper limbs. However by 1989, Hagberg $^{15}$ appreciated the limitations of his own classification-particularly the unsatisfactory nature of the dividing line between diplegia and quadriplegia and the fact that many children change categories as they grow older.

In 2000, the European Collaboration $\mathrm{SCPE}^{10}$ did not include diplegia in its classification because of the inherent ambiguities.

Not surprisingly, all this confusion is mirrored in the standard paediatric textbooks.

Forfar and Arniel $^{16}$ regard diplegia as a clear entity in which the legs are more affected than the arms; the more affected the upper limbs, the lower is intelligence. It is linked to specific cerebral pathologies, which are themselves linked to premature delivery or asphyxia. In Nelson, ${ }^{17}$ diplegia is spasticity of just the legs, with good prognosis for intelligence and seizures. The lesions in the brain are similar in diplegia and quadriplegia, except for more extensive necrotic degeneration of white matter which coalesces into cystic cavities in quadriplegia. In Rudolph, ${ }^{18}$ diplegia requires the legs to have greater spasticity and weakness than the arms. The children are frequently preterm and the deficit is more apparent in wrist extensors and activities of daily living such as self feeding, drawing, or writing. Quadriplegia is determined by symmetric impairment of all four extremities; growth retardation, mental retardation, language disorders, and seizures are common. Avery ${ }^{19}$ describes spastic diplegia as restricted to bilateral spastic involvement of the lower extremities, often associated with normal cognitive function. Quadriplegia is spastic involvement of the extremities, often with orobuccal musculature rendering swallowing and talking difficult.

\section{THE PRESENT SITUATION}

The most recent International Classification of Disease ${ }^{20}$ has a category "spastic diplegia" which it does not further define and another category "diplegia of upper limbs"! However the common ground in the papers we have just discussed appears to be that diplegia is a spastic form of cerebral palsy with lower limbs more affected than upper limbs.

It is however unclear whether presence or absence of prematurity, seizures, or mental retardation is relevant to the definition or just an association. For example, if a child has severe four limb involvement with upper limbs slightly less affected than lower limbs, does presence or absence of the above features such as mental retardation determine whether this is classified as diplegia or quadriplegia?

Even more importantly, what does "more affected" mean and should the comparison be based on clinical signs or function? If comparison is based on 
Table 1 Classifications of cerebral palsy

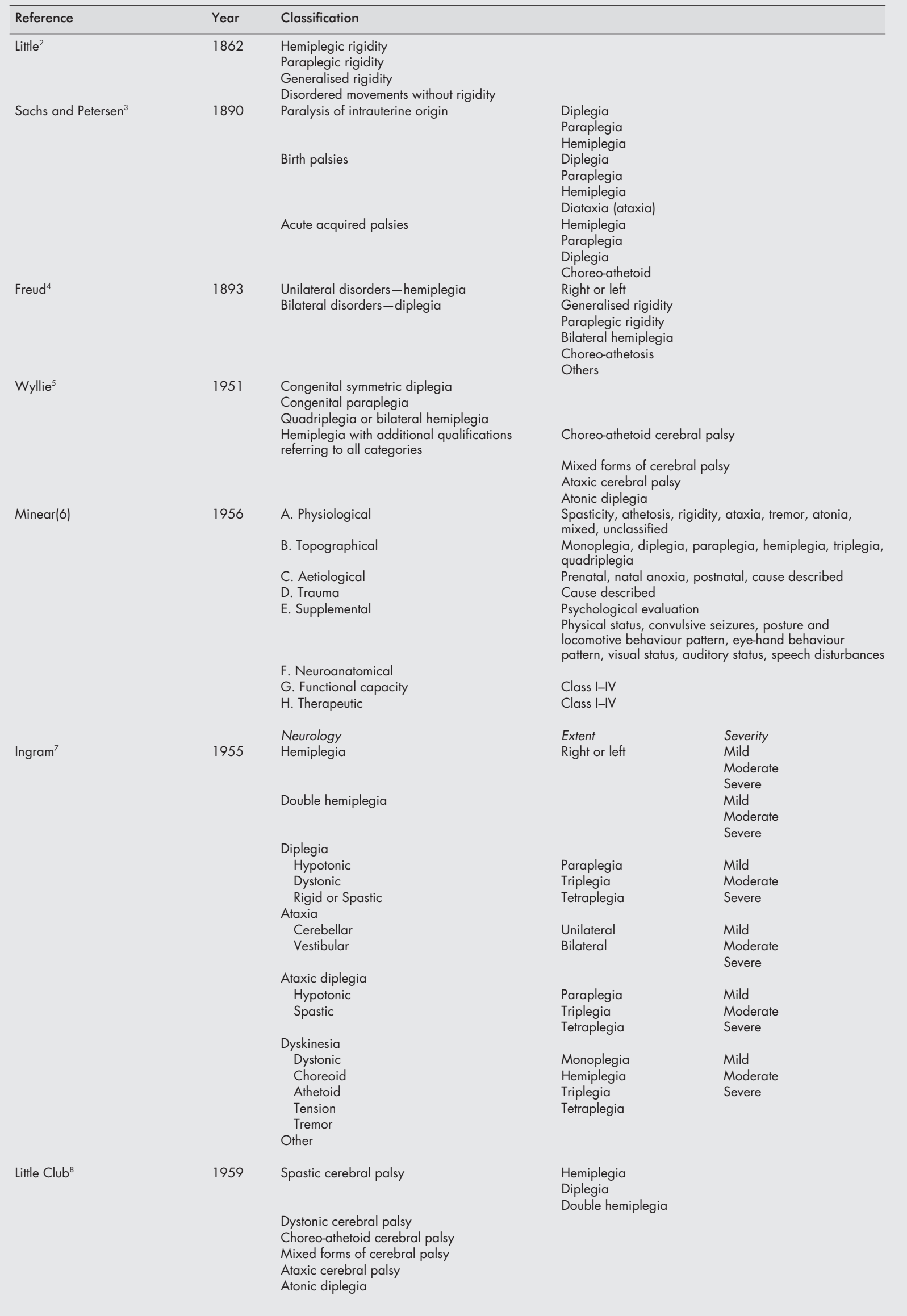




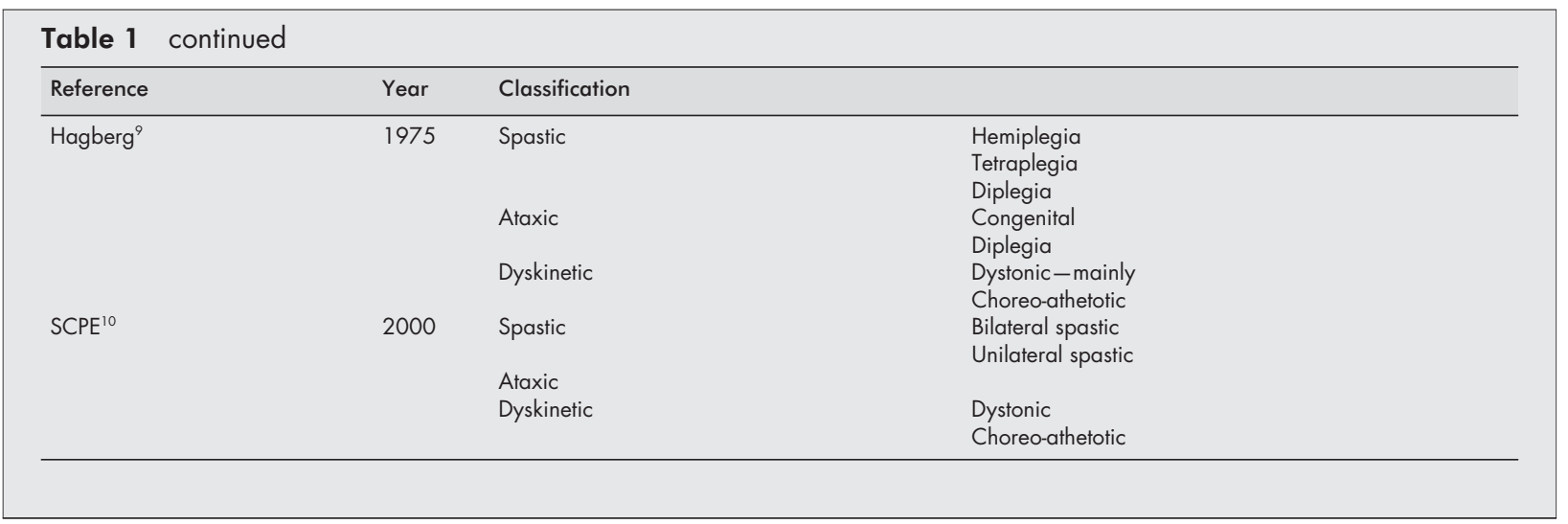

clinical signs, tone, tendon reflexes, and power may be easy to separate at the extremes but very difficult when similar. Signs also vary day to day and with the mood of the child. Further, there is a considerable inter- and intraobserver diagnostic variability in the assessment of clinical signs. ${ }^{21}$ Ashworth developed a scale, tested for reliability-but this validation was in adults and just for hemiplegia. ${ }^{22}$ If comparison is based on function, again this may be straightforward at the extremes but otherwise very difficult. For example, does "walking with difficulty and needing walking aids" mean legs are more or less affected than arms where the child "is not able to write tidily and needs assistance to go to the toilet"?

The North of England Collaborative Cerebral Palsy Survey ${ }^{23}$ found such confusion in the application of clinical signs and assessment of functional severity. A local audit of classification of cases of cerebral palsy revealed 98 with diplegia and 130 with quadriplegia. Of those with diplegia, 58 had moderate to severe functional involvement of upper limbs at age 5 but lower limb function was always the same or worse. Five of these children had severe mental retardation. Of those with quadriplegia, six had nil to mild involvement of the upper limbs, but these six had severe mental retardation, suggesting that the clinician used the presence of severe mental retardation to assign the cerebral palsy to the category quadriplegia.

The term diplegia continues to be used in studies which assume its meaning is understood and uniformly applied. For instance, it is claimed that diplegia is associated with and may be caused by premature birth. ${ }^{24}$ In this study, Powell et al even postulate the existence of a "diplegia factor" which tends to cause premature labour; and impair growth and development if the fetus remains in utero. Their study does not define diplegia and uses the clinical diagnoses from cases notes of children looked after by many paediatricians. In another more recent study, it is suggested that chorioamnionitis may be the cause of spastic diplegia in low birth weight infantsespecially in babies with a normal neonatal ultrasound-but again diplegia is not defined. ${ }^{25}$

\section{NEW ANALYSES OF EPIDEMIOLOGICAL STUDIES}

We shall show that the confusion, which is clear from our review of papers describing the definitions and practical problems in making sense of them, is born out by our review and further analysis of recent epidemiological studies.

Table 2 shows the overall numbers of cases of cerebral palsy and percentages of different subtypes in studies reported from about 1980-which we take as the date by which neonatal intensive care had been introduced in the reporting regions. We have only included studies where all types and severities of cerebral palsy are reported, and where a whole population is reported either on the basis of birth cohort prevalence or population prevalence. It shows that spastic cases as

\begin{tabular}{|c|c|c|c|c|c|c|c|c|c|}
\hline Reference & Study & Duration & $\begin{array}{l}\text { Number of } \\
\text { cases of CP }\end{array}$ & $\begin{array}{l}\text { Number of } \\
\text { spastic cases } \\
\text { of } C P\end{array}$ & $\begin{array}{l}\text { Spastic } \\
\text { cases as \% } \\
\text { of all cases }\end{array}$ & $\begin{array}{l}\text { Unilateral } \\
\text { spastic as \% } \\
\text { of spastic } \\
\text { cases }\end{array}$ & $\begin{array}{l}\text { Diplegia as } \\
\% \text { of spastic } \\
\text { cases }\end{array}$ & $\begin{array}{l}\text { Bilateral } \\
\text { spastic as \% } \\
\text { of spastic } \\
\text { cases }\end{array}$ & $\begin{array}{l}\text { Diplegia as } \\
\% \text { of } \\
\text { bilateral } \\
\text { spastic cases }\end{array}$ \\
\hline 26 & North Italy* & 1980-89 & & & & 35 & 45 & 65 & 69 \\
\hline 27,28 & Denmark & 1979-90 & 908 & 734 & 81 & 23 & 62 & 77 & 81 \\
\hline 29 & North England & 1991-96 & 537 & 499 & 93 & 37 & 23 & 63 & 36 \\
\hline 23 & Northeast England & 1980-96 & 380 & 355 & 93 & 42 & 23 & 58 & 40 \\
\hline 30 & Avon, England & 1979-88 & 237 & 196 & 83 & 39 & 39 & 61 & 63 \\
\hline 31 & Mersey, England & $1984-89$ & 497 & 460 & 93 & 39 & 23 & 61 & 38 \\
\hline 32 & Atlanta, USA & $1985-87$ & 204 & 166 & 81 & 34 & 19 & 66 & 28 \\
\hline $33,34,35$ & Sweden† & 1979-90 & 545 & 470 & 86 & 40 & 51 & 60 & 84 \\
\hline 36 & England and Scotland & $1984-89$ & 1649 & 1334 & 81 & 35 & 22 & 65 & 33 \\
\hline 37 & Slovenia & $1981-90$ & 768 & 651 & 85 & 33 & 43 & 67 & 64 \\
\hline 38 & Western Australia & 1980-94 & 819 & 639 & 78 & 45 & 37 & 55 & 68 \\
\hline 39 & Rome, Italy & $1977-96$ & 282 & 213 & 76 & 33 & 27 & 67 & 40 \\
\hline 40 & Northern Ireland $\ddagger$ & 1977-92 & 960 & 572 & 87 & 43 & 21 & 57 & 36 \\
\hline 41 & Norway & 1980-89 & 46 & 39 & 85 & 49 & 33 & 51 & 65 \\
\hline \multirow[t]{3}{*}{42} & Oxford, England $\S$ & 1984-95 & 967 & 806 & 83 & 40 & & 60 & \\
\hline & Averaged percentage & & & & 85 & 38 & 33 & 62 & 53 \\
\hline & Range & & & & $76-93$ & $23-49$ & $19-62$ & $51-77$ & $28-84$ \\
\hline
\end{tabular}

*Derived from rates in fig 4 of reference 26.

tIncludes 11 acquired cases 1979-82.

‡CP type only available in two thirds of cases.

§lncludes 68 acquired cases. 
Table 3 Proportions of cerebral palsy subtypes in low birth weight babies

\begin{tabular}{|c|c|c|c|c|c|c|c|}
\hline \multirow[b]{2}{*}{ Reference } & \multirow[b]{2}{*}{ Study } & \multicolumn{3}{|l|}{$<2.5 \mathrm{~kg}$} & \multicolumn{3}{|l|}{$<1.5 \mathrm{~kg}$} \\
\hline & & $\begin{array}{l}\text { Unilateral } \\
\text { spastic as \% of } \\
\text { spastic cases }\end{array}$ & $\begin{array}{l}\text { Diplegia as } \% \\
\text { of spastic cases }\end{array}$ & $\begin{array}{l}\text { Bilateral spastic } \\
\text { as \% of spastic } \\
\text { cases }\end{array}$ & $\begin{array}{l}\text { Unilateral } \\
\text { spastic as \% of } \\
\text { spastic cases }\end{array}$ & $\begin{array}{l}\text { Diplegia as \% } \\
\text { of spastic cases }\end{array}$ & $\begin{array}{l}\text { Bilateral spastic } \\
\text { as \% of spastic } \\
\text { cases }\end{array}$ \\
\hline 26 & North Italy & 30 & 55 & 70 & & & \\
\hline 28 & North England & 26 & 32 & 74 & 26 & 36 & 74 \\
\hline 23 & Northeast England & 30 & 31 & 70 & 35 & 31 & 65 \\
\hline 31 & Mersey, England & 30 & 35 & 70 & 33 & 35 & 67 \\
\hline 32 & Atlanta, USA & 25 & 30 & 75 & & & \\
\hline 36 & England and Scotland & 25 & 31 & 75 & 26 & 31 & 74 \\
\hline 38 & Western Australia & 41 & 49 & 59 & 45 & 48 & 55 \\
\hline 39 & Rome, Italy & 25 & 31 & 75 & 22 & 29 & 78 \\
\hline \multirow[t]{3}{*}{42} & Oxford, England & 30 & & 70 & 30 & & 70 \\
\hline & Averaged percentage & 29 & 37 & 71 & 31 & 35 & 69 \\
\hline & Range & $25-41$ & $30-55$ & $59-75$ & $22-45$ & $29-48$ & $55-78$ \\
\hline
\end{tabular}

a proportion of all cases average $85 \%$ (range 76-93\%).

Diplegic cases as a proportion of spastic cases average 33\% (range 19-62\%); whereas diplegic plus quadriplegic cases as a proportion of spastic cases average $62 \%$, with a much smaller range of $51-77 \%$. If one looks just at bilateral spastic cases, the proportion of diplegic cases varies from $28 \%$ to $84 \%$ - a more than threefold difference. Such a large difference is very unlikely to be a real one and is almost certainly a result of the way in which different centres interpret diplegia.

Table 3 shows data from the studies which report by birth weight. In those less than $2.5 \mathrm{~kg}$, diplegic cases as a proportion of spastic cases average $37 \%$ (range $30-55 \%$ ), only very slightly higher than the average of $33 \%$ in all birth weights; and for those less than 1.5 $\mathrm{kg}$, the average is $35 \%$. These findings argue against diplegia being especially associated with either low birth weight or very low birth weight.

\section{DISCUSSION}

Semantically, the word "diplegia" must mean two limbed or two sided weakness. If two limbed, it is bizarre that often three or four limbs are involved. If two sided, it is preferable to use a term such as bilateral with no implication about number of limbs involved. This was Freud's original concept-simple but consistent and understandable.

There is no justification for separating diplegia and quadriplegia. While it is possible that the term diplegia as used by Ingram $^{12}$ may have represented a distinct clinical syndrome before the introduction of neonatal intensive care, we are confident that it does not now. Our analysis of published epidemiological studies has shown that confusion about and inconsistent application of the term diplegia is embedded unknowingly in the studies. When diplegia and quadriplegia are treated separately, there are very unlikely differences between countries which largely disappear when treated together. Further, the supposed association of diplegia with low birth weight is not seen.

Recent advances in imaging support this position. In her magnetic resonance imaging (MRI) studies of children with spastic cerebral palsy, ${ }^{43}{ }^{44}$ KragelohMann found that periventricular leucomalacia and parasaggital lesions were the commonest lesion in preterm infants and term infants. Very similar MRI appearances were responsible for quadriplegic, diplegic, and triplegic syndromes. Severity of motor involvement was related to severity of white matter reduction but the authors could find no justification for separating these syndromes and therefore used the phrase "bilateral spastic cerebral palsy".

In epidemiological studies, more will be gained from an agreed simple logical classification which is uniformly applied than from a complex one which may have internal inconsistencies, be inconsistently applied and influenced by clinical judgement. Our own preference is for that developed by the European Collaboration. ${ }^{10}$

In clinical studies, there may be a need to define more refined groups of children, but these should be described by their neurological and functional deficits, not by shorthand terms such as diplegia or terms such as "more" or "less affected", when like is not being compared with like. An Oxford group addressed this issue in the 1980s. ${ }^{45}{ }^{46}$ Their systematic description would allow the detail necessary for evaluating the effects of different drugs, operations, or physical therapies. An alternative would be to build on the European classification..$^{10}$ For example, the description:

"spastic, bilateral, neurological signs in four limbs, minimal functional involvement of upper limbs, all cognitive abilities" would describe reliably a group of children if the term "minimal" was defined for the age group(s) of children being studied.

\section{ACKNOWLEDGEMENTS}

We are grateful to all members of Surveillance of Cerebral Palsy in Europe (SCPE) for discussions on this subject over four years.

Arch Dis Child 2003;88:286-290

\section{Authors' affiliations}

A F Colver, Senior Lecturer in Community Child Health, Northumbria Healthcare NHS Trust and University of Newcastle upon Tyne, Donald Court House, 13 Walker Terrace, Gateshead NE8 1EB, UK

T Sethumadhavan, Specialist Registrar in Paediatrics, Northumbria Healthcare NHS Trust, North Tyneside General Hospital, Rake Lane, North Shields, UK

Correspondence to: Dr A F Colver, Donald Court House, 13 Walker Terrace, Gateshead NE8 1EB, UK; allan.colver@ncl.ac.uk

\section{REFERENCES}

1 Ingram TTS. A historical review of the definition and classification of the cerebral palsies. In: Stanley FJ, Alberman ED, eds. The epidemiology of cerebral palsies. Spastics International. Oxford: Blackwell Scientific, 1984:1-11.

2 Little WJ. On the influence of abnormal parturition, difficult labours, premature birth and asphyxia neonatorum on the mental and physical condition of the child, especially in relation to deformities. Transactions of the Obstetrical Society of London 1862;3:293-344. Reprinted in Cerebra Palsy Bulletin 1958;1:5-34

3 Sachs B, Petersen F. A study of cerebral palsies of early life. J Nerv Ment Dis 1890;17:295-332

4 Accardo PJ. Freud on diplegia-commentary and translation. Am J Dis Child 1982;136:452-5.

5 Wyllie WG. The cerebral palsies in infancy. In: Feilin A, ed. Modern trends in neurology. London: Butterworth, 1951:125-48.

6 Minear WL. A classification of cerebral palsy. Pediatrics 1956;18:841-5.

7 Ingram TTS. A study of cerebral palsy in the childhood population of Edinburgh. Arch Dis Child 1955;30:85-98.

8 MacKeith RC, Mackenzie ICK, Polani PE. The Little Club: memorandum on terminology and classification of cerebral palsy. Cerebral Palsy Bulletin 1959;5:27-35. 
9 Hagberg B, Hagberg G, Olow I. The changing panorama of cerebral palsy in Sweden 1954-70. 1. Analysis of general changes. Acta Paediatr Scand

1975;64:187-92.

10 Anon. Surveillance of cerebral palsy in Europe: a collaboration of cerebral palsy registers. Dev Med Child Neurol 2000;42:816-24.

11 Balf CL, Ingram TTS. Problems in the classification of cerebral palsy in children. BM 1955;2:163-6.

12 Ingram TTS. The early manifestations and course of diplegia in childhood. Arch Dis Child 1955;30:244-50.

13 Ingram TTS. The neurology of cerebral palsy. Arch Dis Child 1966;41:337.

14 Bax MCO. Terminology and classification of cerebral palsy. Dev Med Child Neurol 1964:6:295-7.

15 Hagberg B. Nosology and classification of cerebral palsy. Giornale di Neuropisichiatrica del Eta Evolutnia 1989:(suppl 4):12-17.

16 Campbell AGM, Mclntosh N, eds. Forfar \& Arneil's textbook of paediatrics, 5th edn. Churchill Livingstone, 1998.

17 Behrman RE, Kleigman RM, Jenson HB, eds. Nelson textbook of pediatrics, 16th edn Philadelphia: W B Saunders Company, 2000.

18 Rudolph AM, Hoffman JIE, Rudolph CD, eds. Rudolph's pediatrics, 20th edn. Appleton \& Lange, 1996

19 Avery ME, First LR, eds. Avery pediatric medicine, 2nd edn. Baltimore: Williams \& Wilkins, 1993.

20 WHO. International statistical classification of diseases and related health problems-tenth revision. Geneva: World Health Organisation 1992.

21 Blair E, Stanley F. Inter-observer agreement in the classification of cerebral palsy. Dev Med Child Neurol 1985;27:615-22.

22 Bohannon RW, Smith MB. Inter-rater reliability of a modified Ashworth scale of muscle spasticity. Phys Ther 1987;67:206-7.

23 Colver AF, Gibson M, Hey EN, et al. Increasing rates of cerebral palsy across the severity spectrum in northeast England 1964-93. Arch Dis Child Fetal Neonatal Ed 2000;83:F7-12.

24 Powell TG, Pharoah POD, Cooke R, et al. Cerebral palsy in low birth weight infants. II. Spastic diplegia: associations with fetal immaturity. Dev Med Child Neurol 1988;30: 19-25.

25 Wheater M, Rennie JM. Perinatal infection is an important risk factor for cerebral palsy in very-low-birthweight infants. Dev Med Child Neurol 2000;42:364-7.

26 Bottos M, Granato T, Allibrio G. Prevalence of cerebral palsy in north-east Italy from 1965 to 1989. Dev Med Child Neurol 1999;41:26-39.

27 Topp M, Uldall P, Langhoff-Roos J. Trend in cerebral palsy birth prevalence in Eastern Denmark: birth-year period 1979-86. Paediatr Perinat Epidemiol 1997; 1 1:451-60.

28 Topp M, Uldall P, Greisen G. Cerebral palsy births in eastern Denmark, 1987-90: implications for neonatal care. Paediatr Perinat Epidemiol 2001;15:271-7.

29 North of England Collaborative Cerebral Palsy Survey. Annual Report 1999. University of Newcastle upon Tyne, 1999.

30 MacGillivray I, Campbell D. The changing pattern of cerebral palsy in Avon. Paediatr Perinat Epidemiol 1995:9:145-55.

31 Pharoah P, Platt M, Cooke T. The changing epidemiology of cerebral palsy. Arch Dis Child Fetal Neonatal Ed 1996;75:F169-73.

32 Murphy CC, Yeargin-Allsopp M, Decoufle P et al. Prevalence of cerebral palsy among ten year old children in metropolitan Atlanta 1985-87. J Paediatr 1993;123:S13-20.

33 Hagberg B, Hagberg G, Olow I. The changing panorama of cerebral palsy in Sweden. V. The birth year period 1979-82. Acta Paediatr Scand 1989;78:283-90.

34 Hagberg B, Hagberg G, Olow I, et al. The changing panorama of cerebral palsy in Sweden. VI. Prevalence and origin during the birth year period 1983-1986. Acta Paediatr Scand 1993:82:387-93.

35 Hagberg B, Hagberg G, Olow I, et al. The changing panorama of cerebral palsy in
Sweden. VII. Prevalence and origin during the birth year period 1987-1990. Acta Paediatr Scand 1996;85:954-60.

36 Pharoah P, Cooker T, Johnson MA, et al. Epidemiology of cerebral palsy in England and Scotland, 1984-9. Arch Dis Child Fetal Neonatal Ed 1998;79:F21-5.

37 Kavcic A, Perat M. Prevalence of cerebral palsy in Slovenia: birth years 1981 to 1990. Dev Med Child Neurol 1998;40:459-63.

38 Watson L, Stanley F, Blair E. Report of the western Australia cerebral palsy register to birth year 1994. TVW Telethon Institute for Child Health Research, 1999:34-5.

39 Miceli M, Di Lallo D, Insogna M, et al. Registro Paralisi Cerebrali Rapporto 1999. Rome: Osservatorio Epidemiologico Regione Lazio, 1999.

40 Parkes J, Dolk H, Hill N. The Northern Ireland Cerebral Palsy Research Project. 1997 Annual Report. Belfast: Health and Social Care Research Unit, The Queen's University of Belfast, 1997.

41 Meberg A, Broch $\mathrm{H}$. A changing pattern of cerebral palsy. Declining trend for incidence of cerebral palsy in the 20-year period 1970-89. J Perinat Med 1995;23:395-402.

42 Oxford Register of Early Childhood Impairments. Annual Report 2000. Oxford: National Perinatal Epidemiology Unit, 2001.

43 Krageloh-Mann I, Petersen D, Hagberg G, et al. Bilateral spastic cerebral palsy-MRI pathology and origin. Analysis from a representative series of 56 cases. Dev Med Child Neurol 1995:37:379-97.

44 Krageloh-Mann I. Magnetic resonance imaging in cerebral palsy. In: Neville B Albright A, eds. Management of spasticity. New Jersey: Churchill Communications, 2000

45 Evans P, Johnson A, Mutch L, et al. Report of a meeting on the standardisation of the recording of the reporting of cerebral palsy. Dev Med Child Neurol 1986;28:547-8.

46 Evans $\mathbf{P}$, Johnson A, Mutch L, et al. A standard form for recording clinical findings in children with a motor deficit of central origin. Dev Med Child Neurol 1989;31:119-20. 